\title{
A New View of the Nature of Reality and the Teaching Higher-Level Cognitive Strategies
}

\author{
Valentyna Bilyk \\ Candidate of Pedagogical Sciences, Associate Professor, National Pedagogical Dragomanov \\ University (Kyiv, Ukraine) \\ E-mail: valya-bilyk@ukr.net \\ https://orcid.org/0000-0002-6860-7728
}

\begin{abstract}
Inesa Sheremet
Candidate of Pedagogical Sciences, Associate Professor, National Pedagogical Dragomanov University (Kyiv, Ukraine)

E-mail: inna.sheremet@i.ua

https://orcid.org/0000-0001-8766-8115
\end{abstract}

The authors state the transition of the modern materialistic worldview paradigm to the idealistic paradigm. The transition to a new view of the nature of reality essentially turns modern education to the defining meanings of Plato's Paideia. The authors reinterpret greek paideia taking into account the current knowledge in science and philosophy. The methods used by the authors have complex crossdisciplinary character. They combine the following basic strategies: the history of ideas, analytics, comparativistics, and phenomenology. The authors conclude that the role of the teacher is changing in the Mental Universe Model or the "Evolving Matter," which forms the basis of an idealistic paradigm. The teacher turns into an important actor of a student's brain neuroprogramming, who is directly responsible for the quality of his work. The authors proposed three basic higher-level cognitive strategies by means of which the teacher embodies the reinterpreted and modernized achievements of the greek paideia. The interrelationship between a teacher and a student gains harmony and provides a joint ascent to the image of a higher idea or to universal consciousness if: 1) a teacher does not provide knowledge, but sets tasks and solves them with a student. 2) the full value of a student's selfrealization depends directly on the usefulness of a teacher's self-realization. 3) choosing a teacher, a student chooses his way of life.

Keywords: cognitive strategies, worldview paradigm, Intelligent Matter, universal mind, universal consciousness, greek paideia

Received: September 25, 2018; accepted: November 21, 2018

Philosophy and Cosmology, Volume 22, 2019: 92-100.

https://doi.org/10.29202/phil-cosm/22/7

(C) Bilyk, Valentyna, 2019

(C) Sheremet, Inesa, 2019 


\section{Introduction}

In the article There Is an 'Unconscious,' but It May Well Be Conscious, which has been published in Europe's Journal of Psychology, the author addresses to an issue of great significance for philosophy of mind: whether there are indeed unconscious mental processes [Kastrup, 2017]. Thus, if at the beginning of the $20^{\text {th }}$ century, thanks to Sigmund Freud, the research of unconscious mental processes was one of the most promising scientific directions, then at the beginning of the $21^{\text {st }}$ century Bernardo Kastrup stated the opposite. He claims that unconscious mental processes do not exist in nature, that "for what we ordinarily and erroneously call 'consciousness' entails metacognition and associative links with the executive ego, in addition to phenomenality proper" [Kastrup, 2017: 559].

The statement of Kastrup is not generally accepted and settled in science. For example, the famous neurobiologist Ran Hassin proves the opposite point of view. He states that unconscious processes exist and play an important role in the functioning of the human brain. However, he argues that "unconscious processes can perform the same fundamental; high-level functions that conscious processes can perform" [Hassin, 2013: 195].

Why did the problem of the existence of subconsciousness and consciousness attract our attention? Understanding the division of labor between conscious processes and unconscious ones is a key point in understanding the nature of reality, in shaping the image of the highest idea, according to which education forms the younger generations. In the article Postmodernism: Philosophy of Education Oleg Bazaluk claims that knowledge of neurobiology of a human brain forms a basis of the modern educational systems [Bazaluk, 2015]. Educational technologies are created and the highest impact on the brain is achieved on their basis. Knowledge of the brain neurobiology forms an empirical basis for the cognitive strategies.

Let us consider to what possible consequences for education, in particular, for teaching the higher-level cognitive strategies, today's reconsideration of the conscious and unconscious processes will lead.

\section{Cosmological paradigms and their impact on education}

In the article Contemporary Cosmological Paradigms and Their Impact on Educational Research, the authors considered the features of influence of the worldview paradigm on the educational researches. As a result of the study, the authors come to the conclusion that "under the influence of the modern hypothesis of the Intelligent Matter and the Mental Universe rethinking of the subject and object of the educational research takes place" [Horokhov \& Zhukova, 2018: 14]. Bernardo Kastrup claims that our culture will move to a new paradigm. "Under this new paradigm, a form of universal mind will be viewed as nature's sole fundamental entity" [Kastrup, 2018: 41]. Thus, reconsideration of the conscious and unconscious processes is not limited to revision of the human ontology. Finally, it leads to the new view of the nature of reality.

The study of Serhii Horokhov and Galina Zhukova forces us to rethink in a new way the fundamental characteristics of the cosmological paradigms. We find that they are not connected with cosmology, with the discovery of the new star systems, a black hole, etc. We discover that the main characteristics of the cosmological paradigms are the consequences of neuroevolution as well, in particular, new facts about the conscious and unconscious processes. In essence, the modern scientific knowledge returns to the ancient understanding of the connection between the macrocosm and the microcosm, when the knowledge of the 
physical processes, the Universe enriches the human ontology, just like new discoveries in the human ontology lead to a new vision of the macrocosm. Horokhov and Zhukova compare the Standard Cosmological Model and the Mental Universe [Horokhov \& Zhukova, 2018]. The Standard Cosmological Model reveals the modern understanding of the evolution of the Universe. However, as the authors state, there is no place for man in it. The model considers the physical and chemical processes, ignoring the conscious and unconscious processes. The Mental Universe Model is based on new understanding of the conscious and unconscious processes. It affirms the universal consciousness as nature's sole fundamental entity. Horokhov and Zhukova consider still the modern Model "Evolving Matter" in which the conscious and unconscious processes are an emanation of the evolving Universe. In the Mental Universe Model and Model "Evolving Matter" the conscious and unconscious processes are the defining characteristics of evolution of the Universe. They define not only the ontology of man, but also they are the key to the disclosure of the defining meanings of the ontology of the cosmos. That is why in modern models of the Universe conscious and unconscious processes are given special attention. They reveal the quality of evolution modeling, explain the most important transitions from physical to chemical processes, and from chemical to neurobiological or mental processes.

A new view concerning neuroevolution, in particular on understanding the division of labor between the conscious processes and unconscious ones, allowed Bernardo Kastrup to state that in the modern period of cultural history there was a change of the worldview paradigm. Instead of mainstream physicalism, which is based on The Standard Cosmological Model, the philosophy of idealism is approved, which follows from the Mental Universe Model or the Model "Evolving Matter". The basis of the new paradigm is formed by the meanings that follow from the reinterpretation of neurobiology of the conscious and unconscious processes. In its turn, the absence of dichotomy between matter and mind changes the basis of educational researches. The new paradigm approves new views on education.

\section{Features of the influence of the idealistic paradigm on the psychology of teaching}

The Model "Evolving Matter" and the Mental Universe Model state the new idealistic view of the nature of reality. Let us consider the changes, which are caused by an idealistic worldview paradigm in education, in particular, in teaching psychology.

First, the understanding of the neuroscience of infant consciousness changes. The question "When does your baby become conscious?" in the idealistic paradigm is incorrect because the child is no longer considered as tabula rasa, i.e. without built-in mental content. In the idealistic paradigm the tabula rasa theory does not work. The birth of a baby is considered as emergence of a new structure of the Earth's Intelligent Matter, ${ }^{1}$ or the form of universal mind. ${ }^{2}$ A child is born as a structure of the Universal consciousness and its ontogenesis is considered as a fragment of self-realization of this general universal structure. In essence, a baby become conscious from the moment of its birth. The beginning of human life is characterized by the launch of neurobiological programs. From the moment of birth, three types of neurobiological programs are clearly visible in the child's brain, the development of which continues throughout the entire ontogenesis:

\footnotetext{
${ }^{1}$ See [Bazaluk, 2018].

${ }^{2}$ See [Kastrup, 2018].
} 
1. Programs that occurred as the result of the Earth's Intelligent Matter Neuroevolution. These programs direct the self-realization of man for the benefit of the earthly civilization, force to think on a substantial scale and create projects for the development of near and far space, etc :;

2. Programs in which the national and cultural context is implemented. These programs are transmitted through genes of parents and form concrete markers of the national and cultural identity;

3. Programs launched by the socio-cultural environment, i.e. formed by society. These are programs that allow man to adapt to the conditions of everyday existence and achieve a state of comfort in the real time.

Thus, in the idealistic paradigm, the psyche of a child instead of tabula rasa appears as a set of specific neurobiological programs aimed at self-realization in ontogenesis.

Secondly, development of a baby as a structure of the Earth's Intelligent Matter or the universal consciousness needs the new educational technologies. Under the dominant idealistic paradigm, the psychology of teaching excludes use of educational technologies, which have the ordering character, as in the tabula rasa theory. The senses of greek paideia come in the forefront, in which education is considered as the ascent of a student and a teacher to the heights of knowledge, to the image of a higher idea. A student and a teacher create harmony in which a teacher is an important actor of the evolution of a student's consciousness. ${ }^{3}$ In the consciousness of a teacher, the consciousness of a child finds support and a role model. A teacher does not teach a child and does not dominate over him. Together they ascend in the universal consciousness stream, everyone in one's own way implementing the neurobiological programs, which are put in them. In the new educational technologies, a teacher is considered as a guide. On the one hand, he determines the path of the consciousness of a student in the universe, his individual entry into the universal consciousness stream. On the other hand, the teacher supports and strengthens this way, professionally influencing on disclosure of the neurobiological programs put in the student's brain. In the idealistic paradigm, a teacher uses not only the educational technologies, but he becomes an important actor in the educational technologies as well.

Thirdly, the educational technologies, that are built on the meanings of greek paideia, force to rethink the psychology applied to teaching. A teacher is transformed from a personalized knowledge repeater into an important neuroprogramming actor of a student's brain. He is responsible for the quality and full value of the development of the neurobiological programs put in a student's brain. Essentially, a teacher takes the same place in the ontogenesis of a student as his parents, but he bears more responsibility. He is a professional and is directly responsible for the quality of a student's brain neuroprogramming. Not delegation of responsibility from one teacher to another, or from teachers to parents becomes the important aspect of psychology teaching. More important is awareness of the personal responsibility for the quality of the guiding. For this reason, a teacher works not only with a student, but also with his parents, with whose help, and with whom he achieves the necessary quality of neuroprogramming. In the idealistic paradigm of the world perception, a teacher is endowed with specific duties towards a student, a student's parents and society. Therefore, the main quality of psychology of teaching is responsibility for the quality of a student's self-realization as a structure of the universal consciousness. A teacher's professionalism is revealed as the neuroevolution of his students, in their contribution to the general stream of the universal consciousness.

${ }^{3}$ See [Bazaluk, 2018a]. 
Thus, in the idealistic view of the nature of reality, a teacher becomes an important actor in a student's brain neuroprogramming, who is directly responsible for the quality of his work. Let us consider with what tools a teacher achieves the quality of his work, i.e. forms harmony with a student and provides a joint ascent to the heights of the universal consciousness.

\section{New higher-level cognitive strategies}

As a rule, the term "cognitive strategies" is used in means of "procedural facilitators", "procedural prompts", "scaffolds" or "thinking about thinking". In the classical sense, cognitive strategies are the tools that serve students to learn effectively, and teachers to achieve the high-quality development of the neurobiological programs put in a student's brain. [Baker et al., 2002]. However, the idealistic worldview paradigm forces one to take a fresh look at the possibilities of the cognitive strategies and rethink their capabilities. Let us reveal the new meanings of the cognitive strategies as a tool with the help of which the teacher embodies the reinterpreted and adapted to modernity the achievements of greek paideia. The main tools of a teacher will be called the higher-level cognitive strategies by us. Let us consider three higher-level cognitive strategies.

The first higher-level cognitive strategy: a teacher does not provide knowledge, but sets tasks and solves them together with a student. In the modern literature, when they write about greek paideia, they imply at least three independent directions in the development of the educational theories that took a start in Antiquity. These are: a) the philosophical tradition, or the school of Plato; b) rhetorical tradition, or the school of Isocrates; c) the traditions of stoicism. In ancient Greece, these schools not only competed with each other, but also united, found compromise solutions, created joint projects. Considering the higherlevel cognitive strategy, we are talking exclusively about the meanings that have emerged in the philosophical tradition, i.e. which are based on Plato's ideas about education.

If a teacher specialized in the traditions of Isocrates' school, mainly on the transferring knowledge to students, in the philosophical tradition the term "knowledge" had a different meaning. Knowledge was understood as the path to wisdom, sophia, and philosophy was understood as wisdom outside the cave, as the highest step of ascent to the image of the highest idea [Heidegger, 1986]. Based on this understanding of knowledge, a teacher, in principle, could not give any knowledge. For Plato and his followers, knowledge was not material. Knowledge was opened to a student at a joint ascent to the image of the highest idea, which Plato formulated as the "idea of good". Neo-Platonists, on the basis of Plato's ideas about ascending to the image of the highest idea, to the Sun, about the dominance of the "idea of good", etc., created the philosophy of idealism that had dominated in the history of culture for several millennia. Only in the last two centuries, the philosophy of idealism replaced the mainstream physicalism. However, as we've showed earlier, the new worldview paradigm heralds the revival of the philosophy of idealism only on the basis of the modern knowledge of the nature of reality. Rethinking the nature of the conscious and unconscious processes, scientists thereby highlight the new meanings of human ontology. The modern level of neurosciences allows us to consider the highest idea, which according to Plato was the "idea of good", more objectively. In the cosmological models, considered by Serhii Horokhov and Galina Zhukova, though the higher ideas differ in names, their meanings have a common basis. The Mental Universe Model and Model "Evolving Matter", as well as the images of Intelligent Matter and universal consciousness as images of the highest idea following from them, are based on Plato's ideas and the philosophy of idealism. 
In the idealistic paradigm, the consciousness of a student and a teacher goes back to the universal consciousness. A teacher sets the tasks and together with the student solves them, which in Plato's terminology means an ascent from one haven to another. Each new task, like a new haven, implies the acquisition of new skills and competencies. This is not a formal acquisition of knowledge, as a market service, but a new qualitative level of development of the neurobiological programs. This is knowledge enriched by practice. This is the link between a student's desire to solve a task and the acquisition of new tools to solve a task. However, the main thing in the formulation of the problem and its solution is the final result, the very fact of climbing and settling in the new haven. The final result of the ascent, the ascent itself as an action, is associated with emotions, with the release of the powerful flows of psychic energy. Emotions, in which nature manifests itself in the conscious and unconscious processes, which mobilize a student to solve tasks of the next level, to move to a new haven, which is even closer to the top, to the Sun, as a way of the higher idea. Therefore, the first higher-level cognitive strategy is not the formal formulation and solution of problems that are used in the modern educational systems, but above all it's knowledge of the nature of conscious and unconscious processes. Exactly, the process of setting and solving problems is built on the base of this knowledge, because awakening of the conscious and unconscious processes and attainment new meanings, in essence, form the process of ascent to the image of the highest idea, to the universal consciousness.

The second higher-level cognitive strategy: the usefulness of a student's self-realization depends directly on a teacher's self-realization. Pierre Hadot opened the gulf that lies between the philosophers who only talk about ascending to the image of the highest idea, and the philosophers who, by their way of life, set an example of the ascending by themselves. [Hadot, 2005]. Wherein, we put Plato's sense in the term "philosopher". We call those people philosophers, who reached the highest step of Paideia, who beheld the Sun as an image of the highest idea, and opened for themselves its meanings. In essence, the second higher-level cognitive strategy uses this idea of Hadot, only in application to teachers. A teacher has to be a philosopher, in Plato's sense, i.e. a person who has reached tops of self-realization and returned back to a cave to help students ascend, perhaps, the bigger tops of self-realization. Teachers who only talk about ascending to the highest idea, teachers who have not taken their place in life and could not fully realize themselves, these are Men, ${ }^{4}$ who should not be allowed to teach. Thanks to Martin Heidegger, a clear understanding was established in German philosophy and education that schools should be separated from the teachers so called Men. In order to help a student fully realize in ontogenesis the neurobiological programs established by nature, the teacher himself must have the experience of ascent, that is, full self-realization in ontogenesis, he should have certain achievements in this ascent, i.e. experience in ascending. A teacher is more than a profession. It is rather a vocation, a state of mind. It was not in vain for Plato that the highest step of Paideia was not an ascent to the image of the highest idea, but a descent for those who remained in the cave, and one's willingness to help them find true freedom. ${ }^{5}$

Therefore, the second higher-level cognitive strategy makes special demands to a teacher. As a key actor in the neuroprogramming of a child's brain, a teacher must have the appropriate leadership qualities. In psychology of teaching the first place belongs not only to the knowledge of a teacher, i.e. his self-realization top, proximity to an exit from a cave, it's more important his psychological stability. It is for a student more important to

\footnotetext{
${ }^{4}$ See [Heidegger, 1961].

${ }^{5}$ See [Heidegger, 1986].
} 
reach his self-realization top. For a teacher, the first place takes the ability to find forces to go down in a cave and again, with a new student or students, to repeat the ascent. In this case, some knowledge and competences are not enough. Psychological stability and leader characteristics of the personality of a teacher is more important here. After all, such descents and ascents a teacher will have to do more than once, is not he? And each time, descents and ascents are not repeated. The neurobiological programs embedded in students' brains are different, so for a teacher, ascending with new students, it is always different; it always takes place in a different way. That is why applied psychology is of paramount importance in teachers' training.

The third higher-level cognitive strategy: choosing a teacher, a student chooses a unique, individual way of life. This strategy again turns us to the ideas of Plato, which Pierre Hadot enriched with the achievements of modern science and philosophy. Namely, a teacher's way of life determines a student's way of life. The third higher-level cognitive strategy puts emphasis between the nominal and real power. This question in relation to politics is considered in the article Dialectics of Nominal and Real Power in the Ukrainian and World Politics [Svyrydenko \& Yatsenko, 2018]. For our study, it is interesting in connection with the distribution of powers between a student, his parents and a teacher. The third higherlevel cognitive strategy affirms that a student owns the real power, and the nominal power belongs to parents and teachers. Pierre Hadot is right in insisting that a teacher's way of life determines a student's way of life. Harmony between a teacher and a student is established primarily through the efforts of a teacher. He is wiser and more sophisticated in ascending to the top, towards the universal consciousness. Therefore, involuntarily, but he dominates in relationship with a student. The fact of domination over a student should be realized by student's parents and a teacher. It does not always benefit a student. As the result, and for this very reason, only a student possesses the real power. A student chooses an acceptable way of ascending to the image of the highest idea. This choice caused by the neurobiological programs put in him. Neither for parents, nor for a teacher, this choice should become a problem, if it is reasoned and grounded. Not always, the neurobiological programs of a teacher and a student are brought in correspondence with each other and are capable to interact at ascension. There are a lot of neurobiological and mental characteristics that cause the discrepancy and irreducibility of programs into one unit. It is important to realize the right choice, leave this choice to a student, and decide on it, make a choice. A student always feels better a teacher and his way of life. Exactly feels, because a teacher has to realize the compatibility or incompatibility with a pupil due to perfection of his brain. Professionalism of the teacher is not in imposing the way to life to the pupil and, perhaps, to bring him not to that top and not to those ideals. Professionalism of a teacher is not in imposing his way of life and, perhaps, not in bringing a student to that top and to those ideals. Professionalism of a teacher is manifested in finding by a student of his individual and unique way of life. In no case, a student should repeat the path of his teacher or parents. A teacher should create the conditions under which the real power, which is formed by the neurobiological programs embedded in a student's brain, would be maximally realized. This is the meaning of the individual ascent to the image of the highest idea: a student ascends with his teacher, but a teacher always remains in the shadow, because it is not his ascent, it is his student's unique and individual ascent. 


\section{Conclusion}

Thus, a new view of the nature of reality brings us back to the origin of the philosophy of idealism. We return back to Plato's Paideia and rethink on the basis of the modern knowledge in science and philosophy. Replacing mainstream physicalism with the philosophy of idealism changes the psychology of teaching. A teacher becomes an important actor in the neuroprogramming of a student's brain. We have considered three basic higher-level cognitive strategies, with the help of which a teacher achieves harmony in relations with a student and provides a joint ascent to the image of the highest idea, or to the universal consciousness.

It means:

1. A teacher does not give any knowledge, but sets tasks and together with a student solves them.

2. The full value of self-realization of a student depends directly on the usefulness of the self-realization of his teacher.

3. Choosing a teacher, a student chooses his way of life.

Using the mentioned above strategies, a teacher provides a complete self-realization of the neurobiological programs, or the implementation of the conscious and unconscious processes. A student achieves the image of a highest idea in his unique and individual way, despite the fact that a teacher is always side by side in his ascent, always is present in the shadow, ready to help, secure and act as a guide. This is the self-realization of the teacher's neurobiological programs.

\section{References}

Baker, Scott, Russell Gersten, and David Scanlon. Procedural Facilitators and Cognitive Strategies: Tools for Unraveling the Mysteries of Comprehension and the Writing Process, and for Providing Meaningful Access to the General Curriculum. Learning Disabilities Research \& Practice. Volume 17, Issue 1, 2002: 65-77.

Bazaluk, Oleg. Postmodernism: Philosophy of Education. Future Human Image. 2 (5), 2015: 9-22.

Bazaluk, Oleg. The Ontology of Existence: the Next Paradigm. Anthropological Measurements of Philosophical Research. 14, 2018: 180-183. https://doi.org/10.15802/ampr. v0i14.151745

Bazaluk, Oleg. The Feature Transformations of the Basic Meanings of Greek Paideia in the Educational Theories in the Middle Ages. Schole, Vol. 12.1, 2018a: 243-258. https:// doi.org/10.21267/AQUILO.2018.12.10428

Hadot, Pierre. Philosophy as a Way of Life: Conversations with Jeannie Carlier and Arnold I. Davidson. Trans. V. A. Vorobyov. Moscow, St.-Petersburg: Stepnoy veter; Kolo Publ, 2005.

Hassin, Ran. Yes it Can: On the Functional Abilities of the Human Unconscious. Perspectives on Psychological Science, 8(2), 2013: 195-207. https://doi. org/10.1177/1745691612460684

Heidegger, Martin. On the Essence of Truth. Translated by John Sallis, 1961. https://aphelis. net/wp-content/uploads/2011/02/Martin-Heidegger-On-the-Essence-of-Truth.pdf

Heidegger, Martin. Plato's Doctrine of Truth. Historical and Philosophical Yearbook. Moscow: Nauka, 1986: 255-275. 
Horokhov, Serhii and Galina Zhukova. Contemporary Cosmological Paradigms and Their Impact on Educational Research. Philosophy and Cosmology, Volume 21, 2018: 1420. https://doi.org/10.29202/phil-cosm/21/2

Kastrup, Bernardo. There Is an 'Unconscious,' but It May Well Be Conscious. Europe's Journal of Psychology. Volume 13, No. 3, 2017: 559-572.

Kastrup, Bernardo. The Next Paradigm. Future Human Image, Volume 9, 2018: 41-51. https://doi.org/10.29202/fhi/9/4

Svyrydenko, Denys, and Olena Yatsenko. Dialectics of Nominal and Real Power in the Ukrainian and World Politics. Ukrainian Policymaker, Volume 2, 2018: 33-40. https:// doi.org/10.29202/up/2/5 